\title{
Comparative Evaluation of BMI, Dental Age, Salivary Alkaline Phosphatase Levels, and Oral Health Status in Children with $\beta$ Thalassemia Major
}

\author{
Sandipamu T Rani ${ }^{1}$, Eddula R Reddy ${ }^{2}$, Merum Kiranmai ${ }^{3}$, Srujana P Mudusu ${ }^{4}$, Saraswathi Srikanth ${ }^{5}$, Suman Jain ${ }^{6}$
}

\begin{abstract}
Purpose: Thalassemia poses clear systemic and oral health problems. Clinicians must be aware of various dental treatment needs in these patients. This study was undertaken to assess body mass index (BMI), dental age, salivary alkaline phosphatase levels, malocclusion, and treatment needs in children with $\beta$ thalassemia major.

Materials and methods: A total of 100 children within the age group of 2-15 years (50 thalassemic and 50 healthy controls) were included. Dental age, oral health status, malocclusion, and intervention urgency index was recorded. Unstimulated whole saliva samples were collected to assess the salivary alkaline phosphatase levels. The recorded data were statistically analyzed.

Results: A significantly greater number of thalassemia children were found to be in the underweight category. A significantly high OHI-S scores and low gingival index scores were observed in thalassemia children. Salivary alkaline phosphatase levels were significantly low in thalassemia children compared to the control group. Intervention urgency index scores were significantly high in thalassemia group of children.

Conclusion: Thalassemia children had low BMI, gingival index scores, salivary alkaline phosphatase levels and higher prevalence of malocclusion, and high $\mathrm{OHI}-\mathrm{S}$ index scores compared to the healthy control group. Intervention urgency index scores revealed greater dental treatment needs in children with thalassemia.

Keywords: $\beta$ thalassemia major, Body mass index, Intervention urgency index, Oral health status, Salivary alkaline phosphatase. International Journal of Clinical Pediatric Dentistry (2019): 10.5005/jp-journals-10005-1641
\end{abstract}

\section{INTRODUCTION}

Thalassemia is a genetic hemoglobin disorder that is prevalent worldwide, with the highest frequencies observed in South East Asia and Africa. ${ }^{1}$ The mean prevalence of thalassemia in India is $3.3 \% .^{2,3}$ Thalassemia is broadly classified into two types based on the deficient quantitative synthesis of either a or $\beta$ chains of hemoglobin. $\beta$ thalassemia is inherited as an autosomal recessive trait owing to mutations in the HBB gene located on chromosome 11. The severity of the disease depends on the nature and presence of mutations in one or both alleles. ${ }^{4}$ The carrier rate of $\beta$ thalassemia gene varies from $1 \%$ to $3 \%$ in southern India to $3-15 \%$ in Northern India. ${ }^{3,5} \beta$ thalassemia exhibits a wide range of clinical spectrum ranging from severe forms ( $\beta$ thalassemia major), milder forms ( $\beta$ thalassemia intermedia), and till clinically asymptomatic ones ( $\beta$ thalassemia minor). ${ }^{6}$

Signs and symptoms of $\beta$ thalassemia major appear within 2 years of life. Affected infants present with severe anemia, jaundice, extreme pallor, decrease physical activity, poor feeding, irritability, and increased somnolence. Diarrhea, recurrent fever, spontaneous fractures, bleeding, susceptibility to various infections, hepatosplenomegaly, and growth retardation are some of the commonly presenting symptoms. ${ }^{4}$ These thalassemia children are susceptible to various infections because of repeated blood transfusions and become transfusion-dependent throughout life to replenish their diminished red blood cell supply. They are mostly at risk of experiencing oral and facial problems owing to bone marrow hyperplasia. ${ }^{7}$ These orofacial abnormalities include wide spacing of teeth, forward drift, and protrusion of maxillary incisors, abnormal anterior open bite, protrusion of maxilla, abnormalities in occlusion, and saddle nose deformity and delayed pneumatization of the maxillary antrum. ${ }^{8}$ Several secondary effects include dental caries, pale-colored gums, burning sensation of tongue, painful
${ }^{1-5}$ Department of Pedodontics and Preventive Dentistry, Kamineni Institute of Dental Sciences, Nalgonda, Telangana, India

${ }^{6}$ Thalassemia and Sickle Cell Society, Hyderabad, Telangana, India

Corresponding Author: Sandipamu T Rani, Department of Pedodontics and Preventive Dentistry, Kamineni Institute of Dental Sciences, Nalgonda, Telangana, India, Phone: +91 8919134284, e-mail: drstranipedo@gmail. com

How to cite this article: Rani ST, Reddy ER, et al. Comparative Evaluation of BMI, Dental Age, Salivary Alkaline Phosphatase Levels, and Oral Health Status in Children with $\beta$ Thalassemia Major. Int J Clin Pediatr Dent 2019;12(4):303-306.

Source of support: Nil

Conflict of interest: None

swelling of salivary glands and dry mouth, and reduced IgA levels, resulting in reduced salivary protection. ${ }^{9}$

Sialometry and sialochemistry can be used to diagnose systemic illnesses, monitor general health, and is an indicator for diseases' risk in relation to oral and systemic health. ${ }^{10}$ Alkaline phosphatase (ALP) is a calcium-phosphorous-binding protein and phosphorhydrolytic enzyme. ALP is important in tooth mineralization.

Hence, the present study was undertaken to evaluate the BMI, dental age, oral health status, and salivary alkaline phosphatase levels in children with $\beta$ thalassemia major.

\section{Materials and Methods}

\section{Sample Selection}

This study was carried out at the Department of Pedodontics and Preventive dentistry, Kamineni Institute of Dental Sciences, 
Narketpally, Nalgonda (Dt), Telangana. A total of 100 children (thalassemic children 50, Normal healthy children 50) within the age range of 2-15 years were included in the study. Thalassemia children were selected from the Thalassemic Society, a part of Hematological Society, Hyderabad and normal healthy children from nearby schools of this locality. Ethical clearance from the institution, headmasters of the schools and the Thalassemic society and informed parental consent were obtained.

\section{Selection Criteria}

The study group included children who were diagnosed previously with $\beta$ thalassemia major. Children who were free of thalassemia and dental caries were taken as healthy controls.

\section{Study Design}

A well-structured proforma was prepared to record the normal demographic data, family history, height and weight, eruption status and eruption sequence, OHI-S, gingival index, and intervention urgency needs index ${ }^{11}$ (Table 1). Intraoral examination and collection of unstimulated saliva samples were carried out in the children of Thalassemic Society, on the day of their routine blood transfusion.
After the completion of intraoral examination, unstimulated saliva sample was collected in sterile plastic containers to analyze the salivary alkaline phosphatase levels. Then these plastic containers were kept immediately in the ice box for transportation to the laboratory. Salivary alkaline phosphatase levels were analyzed using autoanalyzer and the enzyme kit.

\section{Results}

In this study, a greater number of thalassemic group of children (46\%) were found in the underweight category (low BMI) compared to the control group children (22\%). No significant difference was observed between both the groups when chronological and dental ages were compared (Table 2).

Table 3 shows mean plaque index, calculus index, and $\mathrm{OHI}-\mathrm{S}$ index scores in both thalassemic and control group. The thalassemic group of children had higher mean plaque scores and OHI-S scores. This difference in the plaque index scores and OHI-S scores was found to be statistically significant $(p<0.05)$. However, no significant difference was seen in gingival index scores between the two groups of children. The mean salivary alkaline phosphatase level was $20.12( \pm 15.62)$ in thalassemia children, which was

Table 1: Data recorded/recorded parameters

\begin{tabular}{|c|c|c|}
\hline S. no. & Parameters & Criteria \\
\hline 1 & BMI & Height $(\mathrm{cm}) /$ weight $(\mathrm{kg}) \times 100$ (underweight, healthy, and overweight or obesity) \\
\hline 2 & Dental age & Age depending on the last erupted tooth in the oral cavity \\
\hline 3 & DMFT/deft (WHO) & Both for permanent and primary teeth were recorded. \\
\hline \multirow[t]{10}{*}{4} & $\mathrm{OHI}-\mathrm{S}$ & Plaque index (silness and LOE'64) \\
\hline & & $0=$ no plaque \\
\hline & & $1=$ plaque present on some \\
\hline & & $2=$ plaque present on all surfaces covering less than one half \\
\hline & & $3=$ plaque extending more than one half of these surfaces \\
\hline & & Calculus index \\
\hline & & $0=$ absence of calculus. \\
\hline & & $1=$ supragingival calculus (not more than $1 \mathrm{~mm}$ ) \\
\hline & & $\begin{array}{l}2=\text { moderate amount of supragingival and sub gingival calculus or sub gingival } \\
\text { calculus alone }\end{array}$ \\
\hline & & $3=$ an abundance of supra gingival and sub gingival calculus \\
\hline \multirow[t]{4}{*}{5} & Gingival index & $0=$ normal gingiva \\
\hline & & $1=$ mild inflammation; slight change in color; no bleeding on probing \\
\hline & & 2 = moderate inflammation; redness, edema; bleeding on probing \\
\hline & & $\begin{array}{l}3=\text { severe inflammation; marked redness and edema; tendency to spontaneous } \\
\text { bleeding }\end{array}$ \\
\hline \multirow[t]{5}{*}{6} & Malocclusion & Angle's molar relation \\
\hline & & Upper anterior proclination \\
\hline & & Upper and lower anterior crowding \\
\hline & & Anterior crossbite \\
\hline & & Anterior open bite \\
\hline 7 & Salivary alkaline phosphatase & Lifechem $^{T M}$ Alkaline Phosphatase kit—LR (Lifechem Ltd, Hyderabad, India) \\
\hline \multirow[t]{5}{*}{8} & $\begin{array}{l}\text { Intervention urgency index } \\
(\mathrm{WHO} 2013)^{9}\end{array}$ & $0=$ no treatment needed \\
\hline & & $1=$ preventive and routine treatment \\
\hline & & $2=$ prompt treatment (scaling) \\
\hline & & $3=$ urgent treatment required due to pain or infection \\
\hline & & $4=$ referred for comprehensive evaluation \\
\hline
\end{tabular}


Table 2: Comparison between chronological age and dental age between thalassemic and control group children

\begin{tabular}{lll}
\hline Ages & Thalassemia group & Control group \\
\hline Chronological age & $8.68 \pm 3.26$ & $10.63 \pm 2.26$ \\
Dental age & $7.52 \pm 3.24$ & $10.02 \pm 2.24$ \\
$p$ value & 0.07 (NS) & 0.061 (NS) \\
\hline
\end{tabular}

NS, not significant

Table 3: Comparison of OHI-S index values between thalassemic and control group children

\begin{tabular}{llll}
\hline & \multicolumn{2}{c}{ Groups } & \\
\cline { 2 - 3 } Oral health status & Thalassemia & Control & p value \\
\hline Plaque index & 1.07 & 0.78 & $0.02^{*}(\mathrm{~S})$ \\
Calculus index & 0.65 & 0.68 & 0.84 (NS) \\
OHI-S & 1.72 & 1.46 & $0.006^{*}(\mathrm{~S})$ \\
Gingival index & $0.88 \pm 0.55$ & $0.82 \pm 0.48$ & $0.56(\mathrm{NS})$ \\
Salivary alkaline & $20.12 \pm 15.6$ & $56.46 \pm 97.5$ & $0.01^{*}(\mathrm{~S})$ \\
phosphatase levels & & & \\
Intervention urgency & $0.84 \pm 0.91$ & $0.40 \pm 0.63$ & $0.000^{*}(\mathrm{~S})$
\end{tabular}

index

*Statistically significant

S, statistically significant; NS, not significant

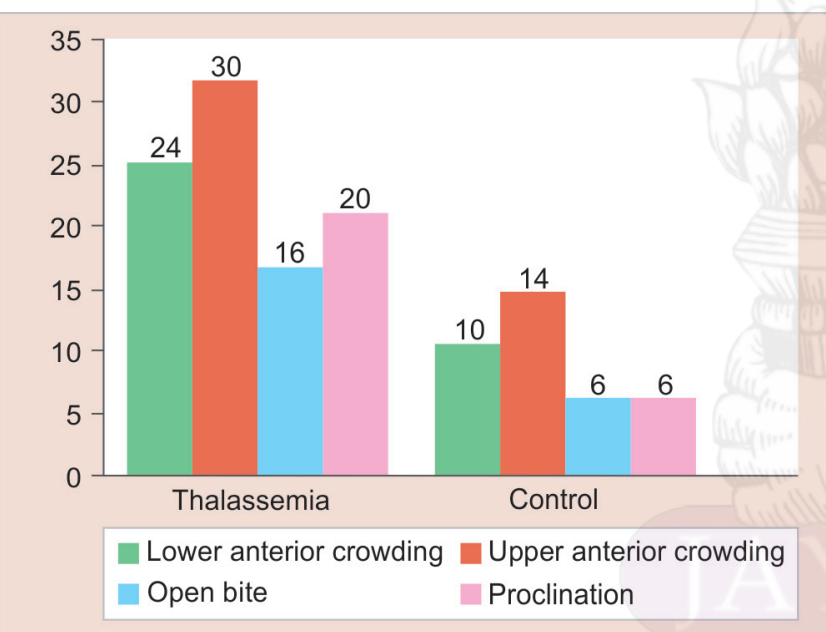

Fig. 1: Prevalence of malocclusion among thalassemic and control group children

significantly low $(p<0.05)$ compared to the levels $56.46( \pm 97.5)$ of the control group children. The mean intervention urgency index scores of thalassemic children and control group children were 0.84 \pm 0.91 and $0.40 \pm 0.63$ respectively, indicating greater treatment needs for thalassemic children, which was found to be statistically significant $(p=0.000)$.

Figure 1 shows that the thalassemic group of children presented with significantly greater malocclusion problems such as upper and lower anterior crowding, proclination of upper and lower anterior teeth, and open bite compared to the control group. This difference was found to be statistically significant $(p<0.05)$.

\section{Discussion}

The main purpose of this study was to evaluate the relationship between the oral health status and salivary alkaline phosphatase levels in $\beta$ thalassemia major children. Children with thalassemia have been found to have lower bone density, slow growth, delayed puberty, bone problems, hepatosplenomegaly, etc. ${ }^{12}$ These children undergo transfusion therapy at very early ages and will be on a regular blood transfusion, thus reducing the typical facial characteristics and its related problems. ${ }^{13}$

In this study, no correlation was found between chronological age and dental age and showed no signs of delayed eruption with proper eruption timing and eruption sequence of the dentition. Similar findings were reported by Laor et al. ${ }^{14}$ in $\beta$-thalassemia major patients.

In the present study, $63 \%$ of children in the thalassemia group had dental caries with a mean DMFT/deft of 2.6. However, these DMFT/deft scores were comparatively lower compared to the studies reported. The DMFT index showed a slightly higher value ${ }^{4,13,15}$ in the thalassemia group but with no significant difference ${ }^{16,17}$ between the groups. The association of DMFT in these children is still a matter of concern.

The thalassemic children had a high plaque index, $\mathrm{OHI}-\mathrm{S}$ scores, and low gingival index scores compared to healthy controls in this study. Mild gingivitis was observed in most of these children, which could be due to the lack of awareness of proper maintenance of oral hygiene measures or may be due to more concentration on the systemic condition compared to oral health. On the contrary, no significant difference in oral hygiene status between thalassemia and control groups was reported. ${ }^{13,15-18}$ In contrast, Bucci et al., ${ }^{19}$ Hattab et al., ${ }^{20}$ and Rajajee et al. ${ }^{4}$ reported a higher prevalence of gingivitis in thalassemic children.

The thalassemic group of children presented with more malocclusion problems such as upper and lower anterior crowding, anterior open bite and upper and lower anterior proclination compared to healthy control children. Orthodontic problems such as crowding, extreme maxillary overjet, crossbite, and oral breathing are mainly implicated in gingival disease as stated by Helm et al. ${ }^{21,22}$ A similar greater prevalence of malocclusion in thalassemic subjects was reported. ${ }^{17,23}$ On the contrary, a low prevalence of malocclusion was reported. ${ }^{4}$

In this study, the control group children who were free of dental caries were included considering the fact that it would alter salivary alkaline phosphatase levels, as this enzyme helps in tooth mineralization. Concentrations of biochemical components in saliva play an important role in oral diseases, but only few studies examined this in connection with thalassemia major. ${ }^{24}$ Alkaline phosphatase (ALP) is detected in the parotid, submandibular, and minor salivary glands as well as in desquamated epithelial cells, leucocytes, and bacteria from dental plaque. ALP is considered as an important indicator of bone formation and is a phenotypic marker of osteoblast cells. High levels of ALP are seen in systemic conditions such as hyperphosphatasia, obesity, chronic kidney disease, liver, bone, and gingival problems; and in growing children. Low alkaline phosphatase levels are present in malnutrition, when there is deficiency of vitamins and minerals and decreases with age. In the current study, a significantly lower salivary ALP levels were present in thalassemia major children compared to normal healthy children, which could be due to malnutrition. When body mass index was assessed, a greater number of children of thalassemia major were of underweight category. It was also reported that salivary IgA, calcium, phosphorous, sodium, potassium, and urea were found to be significantly lower in thalassemic younger children. ${ }^{13,25}$

Intervention urgency needs index (WHO, 2013) indicates the need for intervention to be rendered. The scores in this study group 
children revealed greater treatment needs towards preventive and therapeutic approaches in the maintenance of oral health.

\section{Limitations of the Present Study}

This study was carried out in small group of children. Alkaline phosphatase levels vary with multiple factors such as age, gender, skeletal maturation, and systemic conditions. These salivary ALP levels were not correlated with serum ALP levels.

\section{Conclusion}

Thalassemia major is a genetic hematological disorder that affects not only the general health but also the oral health of an individual. Utmost attention should be focussed on obtaining information about thalassemia in children before subjecting to a guaranteed safe dental management. In the present study, thalassemia children showed various oral health problems such as lower body mass index and gingival index scores, greater plaque index, OHI-S scores, and malocclusions compared to normal healthy children. There was no correlation with dental age, eruption timing, pattern, and sequence of the dentition. Intervention urgency index scores revealed greater treatment needs in thalassemia children. Hence, preventive and therapeutic approaches should be directed not only toward dental treatment but also with a special emphasis on creating awareness and educating the parents about dental diseases and various management approaches.

\section{References}

1. Singh J, Singh N, et al. Dental And Periodontal Health Status of Beta Thalassemia Major and Sickle Cell Anaemic Patients: A Comparative Study. 2013;5(5):53-58.

2. Yaish HM. Thalassemia. http://www.Emedicine.com/PED/topic 2229. htm. Accessed 6th August. 2007.

3. Verma IC, Choudary VP, et al. Prevention of Thalassemia. A necessity in India. Indian J Pediatr 1992;59:649-654. DOI: 10.1007/BF02859390.

4. Rajajee KTSS, Jampanapalli SR, et al. Prevalence of Dental Caries, Oral Hygiene Status, Malocclusion Status and Dental Treatment Needs in Thalassemic Children - A Cross Sectional Study. Sch Acad J Biosci 2017;5(1):41-46.

5. Manglani M, Lokeshwar MR, et al. 'NESROFT' - an effective screening test for $\beta$ thalassemia trait. Indian Pediatr 1997;34:703-708.

6. Haddad A, Tyan P, et al. $\beta$ thalassemia Intermedia: A Bird's - eye view. Turk J Hematol 2014;31(1):5-16. DOI: 10.4274/Tjh.2014.0032.
7. Hoffbrand AV, Lewis SM, et al. Post Graduate Hematology, 4th ed. Oxford: Butterworth Heinemann; 1999.

8. Pirinccioglu AG, Akpolat $\mathrm{V}$, et al. Bone density in children with beta thalassemia major in Diyarbakir. Bone 2011;49:819-823. DOI: 10.1016/ j.bone.2011.07.014.

9. Aldallal S, AlKathemi M. Orodental Considerations in Thalassemia Patients. J of Haematol and Blood Disord 2016;2(2):205.

10. De Almeida PDV, Gregio AMT, et al. Saliva composition and functions: a Comprehensive Review. J Contemp Dent Pract 2008;9(3):72-80. DOI: 10.5005/jcdp-9-3-72.

11. WHO. Oral health Surveys: Basic Methods. 5th ed. Annexure 2. p. 85.

12. Cooley T, Lee P. A series of cases of splenomegaly in children with anaemia and peculiar bone changes. Trans Am Pediatr 1925;37:29-30.

13. Dhote $\mathrm{V}$, Thosar $\mathrm{N}$, et al. Evaluaiton of oral hygiene status and salivary biochemistry of patients with Thalassemia major: a clinical study. IOSR-JDMS J Med Dent Sci 2015;14(12):98-102.

14. Laor E, Garfunkel A, et al. Prevalence of Orofacial complications in Iranian patients with $\beta$ thalassemia major. Iranian J Publ Health 2007;36:43-46.

15. Al- Wadhani AM, Taani DQ, et al. Dental diseases in subjects with beta thalassemia major. Community Dent Oral Epidemiol 2002;30(6): 418-422. DOI: 10.1034/j.1600-0528.2002.00012.x.

16. Qureshi A, Chaudhry S, et al. Is oral health status of children with $\beta$ thlalassemia worse than that of their normal counterparts? J Khyber Colle Dent 2010;1(1):4-7.

17. Arora M, Nayeemuddin SM, et al. Growth impairment and Dental caries in Thalassemia Major Patients. Indian J Clin Anat Physiol 2014;1:15-20.

18. Kaur N, Hiremath SS. Dental caries and gingival status of 3-14 year old beta thalassemia major patients attending paediatric OPD of Vanivilas hospital. Banglore Arch Oral Sci Res 2012;2:67-70.

19. Bucci $E$, Muzio LO, et al. $\beta$-thalassemiated implicazioni odontostomatologiche. Minerva Stomatologica 1990;39:35-38.

20. Hattab FN, Hazza'a AM, et al. Caries risk in patients with thalassemia major. Int Dent J 2001;51:751-765.

21. Helm S, Petrsen PE. Causal relation between malocclusion and periodontal health. Acta Odontol Scand 1989;47:223-238. DOI: 10.3109/00016358909007705.

22. Schlott WJ. Occlusion and dentl adisease. Dental Today 1999;18:72-77.

23. Mehdizadhe M, Zamani G. Orodental complications in patients with Thalassemia. J Dent Res 2008;5(1):17-20.

24. Siamopoulou-Mavridou A, Mavridis A, et al. Flow rate and chemistry of parotid saliva related to dental caries and gingivitis in patients with thalassemia major. Int J Clin Pediatr Dent 1992;2:93-97. DOI: 10.1111/j.1365-263X.1992.tb00016.x.

25. Madhok S, Madhok S. Dental considerations in Thalassemic patients. IOSR-JDMS 2014;13:57-62. DOI: 10.9790/0853-13645762. 